\title{
As tecnologias da informação e comunicação e a educação à distância'
}

\author{
Comunication and information technologias and distance learning
}

\author{
Mônica Elisa Dias Pons² , José Cardoso Sobrinho³ , José Martinho Rodrigues Remedi ${ }^{4}$ \\ I Trabalho referente ao Edital n. I7/NTE/UAB - 2012 \\ ${ }^{2}$ Professora da UFSM - Campus Silveira Martins, Doutora em Comunicação Social, \\ ${ }^{3}$ Professor da UFSM - Campus Silveira Martins, Doutor em Engenharia Agrícola, \\ ${ }^{4}$ Professor da UNISC, Doutor em História
}

\begin{abstract}
Resumo
O presente texto discute as relações das Tecnologias de Informação e Comunicação (TICs) com os desafios da Educação à Distância (EAD). A partir de McLuhan e Castells, analisar-se-á o contexto social em que grandes transformações tecnológicas produziram novos meios e linguagens comunicacionais, principalmente desde a década de 60 do século passado, partindo da chamada "aldeia global" e desembocando na "galáxia da internet". Por outro lado, se tecnologia e linguagens avançaram exponencialmente em suas potencialidades comunicacionais, ainda é necessário compreenderem-se as formas com que os usuários se relacionam com essas mudanças e quais os instrumentos/mecanismos empregam para ler a rede, para tanto utilizaremos as classificações de leitor no espaço cibernético descritas por Santaella; e baseados em seus conceitos, apontar-se-á para a necessidade de se buscar a qualificação do leitor/usuário do EAD em um "leitor imersivo".
\end{abstract}

Palavras-chaves: Tecnologias de Informação e Comunicação; Educação à Distância; Leitor imersivo

\begin{abstract}
The following paper discusses the relationship of Information and Communication Technologies (ICTs) with the challenges of Distance Education (DE), from McLuhan and Castells will be examined the social context in which major technological changes have produced new media and languages communication, most of all, since the 60s of last century, starting with the so-called "global village" and ending in the "galaxy internet". On the other hand, if technology and language had grown exponentially in their communication capabilities, Yet it is required to understand the ways in which users are related to these changes and which tools/ mechanisms are used to read the network, therefore will be using the ratings reader in the cyberspace described by Santaella, and based on their concepts, we will be aiming to the need to pursue the qualification of the reader/ user of DE in an "immersive reader".
\end{abstract}

Keywords: Information and Communication Technologies; Distance Education; Immersive reader. 
"...mesmo a melhor e mais útil tecnologia do mundo não pode impor-se a um público não preparado. Porque não pode haver espaço para ela na nossa psicologia coletiva."

Derrick de Kerckhove, 2009.

\section{INTRODUÇÃo}

Ao se refletir sobre as possibilidades das Tecnologias de Informação e Comunicação (TICs) no contexto da Educação a Distância (EAD), necessariamente impõe-se a análise das intensas e rápidas transformações que os sucessivos modelos de comunicação passaram no século passado, principalmente, a partir da década de 60. A invenção da escrita, da fotografia, do telégrafo, do jornal, do telefone, do cinema, do rádio, da televisão e da Internet mostram como a nossa história se confunde com a história do surgimento das mídias comunicacionais.

Na década de 60, quando a televisão, enquanto instrumento de disseminação de informações, provocava profundas transformações na forma do indivíduo ver, entender, compreender, digerir a informação, Marshall McLuhan, teórico canadense por muitos apontado como um dos primeiros visionários da rede mundial pontificou "a nova interdependência eletrônica recria o mundo à imagem de uma aldeia, uma aldeia global" (MCLUHAN, 1962, p. 31). Ele se referia a uma nova forma de organização social proporcionada pelas mídias eletrônicas, que, ao alterar os processos cognitivos, suplantariam a cultura impressa. A partir dessa mudança, para McLuhan, os meios eletrônicos levariam a humanidade a uma identidade coletiva com base tribal - aldeia global. Antes disso, a cultura visual dominante seria fragmentária (MCLUHAN, 1962). Desse momento em diante passa-se a entender a possibilidade dos meios eletrônicos romperem toda e qualquer barreira física, geográfica, criando um ambiente potencialmente propício para aos processos comunicacionais. Em função do cenário contextualizado na época, parecia aceitável a ideia de uma comunicação unidirecional, dos meios para o público.

É a partir do surgimento da Internet, a ideia de aldeia global é modificada pelo conceito de sociedade em rede. Vivemos o contexto da era da informação, numa sociedade em rede (CASTELLS, 1999). A aparição das mídias exigiu, em boa parte das vezes, um realinhamento no papel desempenhado pelas mídias anteriores, sempre com vistas à garantia de manutenção das mesmas. O surgimento da Internet, a grande rede atual, produz um novo meio de comu- nicação, de interação e de organização social (CASTELLS, 1999). Sinteticamente, a Internet é o meio de comunicação e de relação sobre a qual se baseia uma nova forma de sociedade, nominada por Castells de "sociedade em rede". A nova rede propõe uma espacialidade própria:

A era da internet foi aclamada como o fim da geografia. De fato, a internet tem uma geografia própria, uma geografia feita de redes e nós que processam o fluxo de informação gerados e administrados a partir de lugares. Como a unidade é a rede, a arquitetura e a dinâmica de múltiplas redes são as fontes de significados e função para cada lugar (CASTELLS, 2003, p. 170).

Ao comentar os avanços da Internet que surgiram com as plataformas nomeadas redes sociais da internet, Lúcia Santaella diz o seguinte,

[...] que o conceito de redes sociais é mais amplo do que rede sociais na web, pois podem existir redes sociais fora da web. Entretanto, a internet incrementou grandemente as possibilidades de formação, desenvolvimento e multiplicação de redes sociais. A característica principal dessas redes de interação incessante está na dinamicidade e na emergência, adaptação e auto-organização que são próprias dos sistemas complexos e que se expressam, no caso, em comportamentos coletivos descentralizados (SANTAELLA, 2010, p. 272).

Uma verdadeira revolução de forma e conteúdo da comunicação através da internet. Com a chegada das tecnologias da segunda geração da internet, abre-se um terreno que começa a ser explorado em suas possibilidades educacionais, no EAD. E como toda atividade exploratória, conhece-se pouco do que vai se descortinar logo à frente. Potencialmente as TICs apresentam-se como importantes ferramentas nesse processo comunicacional na educação. Pretendemos, mais adiante, expor a necessidade de investigarmos as diferentes formas de leitura do ciberespaço pelos usuários do EAD para que tenhamos um aproveitamento maior do processo pedagógico no meio virtual.

\section{A Revolução Digital nos dias atuais}

Para o momento em que vivemos quando falamos em revolução digital os eventos mais arrebatadores são as redes sociais baseadas na internet e sua, cada vez maior, mobilidade. As transformações proporcionadas pela internet no mundo atual já são várias. Os próprios conceitos de tempo e espaço estão em xeque. A contração do 
tempo, cada vez mais curto, mesmo comparando com a redução que foi provocada pelo surgimento do telefone, e aliada com relativos baixos custos financeiros, abrindo-se o potencial para a troca rápida de informação em grandes volumes. $\mathrm{O}$ espaço potencializa-se em sua nova face virtual, mimetizado do espaço real em ambientes virtuais ou jogos interativos. Muito embora a transposição do mundo real para o virtual não seja um momento mágico e de melhoria de padrões culturais e científicos. Na comunicação, por exemplo, discute-se a transposição das mídias tradicionais para os diversos suportes virtuais sem que sejam saneados os velhos vícios, ou seja, nem sempre a internet "moderniza" os conteúdos comunicacionais.

No entanto, o pesquisador Don Tapscott, em uma visão bastante otimista, aposta na chegada da geração internet (define como geração internet aqueles nascidos na década de 1977 a 1997) ao mercado de trabalho para a solução de grande parte dos "vícios" das gerações anteriores, pelo fato desta geração ter sido criada usando a internet, ela estaria mudando todas as instituições sociais, desde as empresas até os governos (TAPSCOTT, 2010). Não podemos deixar de ressaltar que em que pese a pesquisa levada a cabo por Tapscott incluísse jovens de várias localidades do mundo, inclusos aí brasileiros, o foco principal eram os jovens canadenses e norte-americanos. Assim que é conveniente relativizar o seu retrato geracional com as devidas diferenças sociais e culturais. Para o Brasil, o atraso no acesso às tecnologias de ponta só recentemente está sendo equalizado, mesmo assim não alcança a grande maioria de nossos jovens.

Assim que descartado o determinismo tecnológico, podemos perceber as mudanças comportamentais significativas na geração denominada "nativa digital" e elas ocorrem em altíssima velocidade. É perceptível que novas formas de comunicação se instalam no contexto do mundo digital, tanto individualmente com blogs e sites como de forma coletiva através de redes sociais.

Nesta revolução digital, as mídias passaram a se transfigurar, quando uma mídia se torna digital, seus traços de superfície quase não mudam, mas ao mesmo tempo sofrem grandes alterações e gradualmente passa a ser utilizada de modo diferente. Por exemplo, a questão da portabilidade; podemos assistir a um programa, fazer um download e disponibilizá-lo em uma diversidade de dispositivos tecnológicos. Hoje, deparamo-nos com o que Lev Manovich chama de born digital (nascidas digitais), ou seja, mídias que surgem do potencial do computador para criar linguagens que lhe são próprias (MANOVICH, 2001). O teórico da comunicação Jean-Louis Weissberg nos lembra que, em 1997, Dominique Carré já apontava para duas questões referentes à mobilidade: a ubiquidade e a onipresença. A ubiquidade salienta a coincidência entre deslocamento e comunicação, o usuário comunica-se durante o deslocamento. Já a onipresença vai ocultar o deslocamento e permitir ao usuário continuar suas atividades mesmo estando em outro lugar (WEISSBERG, 1999, p. 120). Os espaços deixam de ser territoriais, passam a ser espaços híbridos/ rede, o que Lemos (2008) vai chamar de territórios informacionais. A revolução da internet possibilitou uma fusão de várias estruturas e ferramentas da comunicação interativa móvel e comunicação com fio ou sem fio que também criaram um espaço próprio, o ciberespaço, um domínio compartilhado pelo setor público e privado. Nos últimos anos, evidenciou-se a necessidade de democratização do acesso à educação para atender uma grande massa de educandos. Nesse sentido, a educação a distância que inicialmente era realizada através de correspondência, depois através do rádio, TV e materiais impressos, expandiu significativamente com o advento das tecnologias de informação e comunicação. Essas tecnologias trouxeram novas perspectivas para o suporte de ambientes digitais de aprendizagem utilizados por universidades, escolas, centros de ensino, organizações empresariais, entre outros. Entende-se que estudar o uso dessas tecnologias e os usuários é uma necessidade para pensarmos sobre as potencialidades de desenvolvimento de mecanismos que auxiliem no constante aperfeiçoamento dos processos educacionais interativos no âmbito interno e externo da instituição.

Mas sempre é bom evidenciar uma das mais problemáticas facetas da revolução tecnológica que vivemos, ela aguça o consumismo sem fim e a sensação de irrealização de seus agentes individuais mais costumeiros, como diz Kerckhove:

$\mathrm{Na}$ verdade, parecemos querer que as nossas máquinas, seja um carro ou um computador, sejam dotadas de poderes muito superiores ao uso que delas podemos fazer. Embora poucos dentre nós considerassem seriamente a hipótese de se tornarem corredores de automóveis, e muito menos a possibilidade de treinar, queremos que o nosso Toyota tenha uma velocidade máxima equivalente ao dobro da velocidade limite na autoestrada. O fotógrafo amador pode não colocar a hipótese de carregar as compras da loja para casa, mas preferirá de boa vontade carregar o peso do equipamento, mesmo durante uma subida à montanha, a ser encontrado sem o último produto da Nikon ou da Minolta. A partir do 
momento em que mexem com os computadores, as nossas crianças desenvolvem uma espécie de vício que as faz berrar e espernear se os seus programas favoritos demoram mais do que um nanossegundo a carregar (KERCKHOVE, 2009, p. 21).

A relação homem-máquina, há algumas décadas, já não se configura mais como uma relação mecanicista, quanto maior a evolução tecnológica, maiores são as perturbações e, portanto, maior o quadro de complexificação dos sujeitos.

$\mathrm{Na}$ renomada pesquisadora Sherry Turkle encontramos que:

O aspecto subjetivo da tecnologia não está no que a informática faz por nós, mas no que ela faz conosco. Tento interpretar a questão de maneira a abrir espaço, na discussão sobre o virtual e seus descontentamentos (ou satisfação), para a importância do sonho contido na comunicação quase instantânea. Isso também pode ser um cimento que dá as pessoas o sentimento de "pertencimento". Falo da sensação de que, num grupo de discussão on-line, escrevo e depois, imediatamente, alguém pode retomar a minha ideia, desenvolvê-la e remeter-me alguma coisa. Tais gratificações são estimulantes e produzem um sentimento de filiação" (TURKLE, 1999, p. 121).

O indivíduo, na atualidade, através dos meios de comunicação e dos dispositivos tecnológicos disponibilizados busca permanentemente adaptar-se a essa situação, deparamo-nos com um cenário que influencia todos os campos da vida humana: social, político, econômico, cultural, entre outros. A tecnologia pode representar um importante instrumento de manifestação individual no coletivo.

Pensando na sociedade contemporânea, a concepção de espaço-tempo foi modificada a partir da revolução digital e se percebe essa mudança também na comunicação. Massimo Di Felice, sobre a comunicação digital nos coloca que:

[...] apresenta-se como um processo comunicativo em rede e interativo. Neste, a distinção entre emissor e receptor é substituída por uma interação de fluxos informativos entre o internauta e as redes, resultante de uma navegação única, e individual que cria um rizomático processo comunicativo entre arquiteturas informativas (site, blog, comunidades virtuais, etc), conteúdos e pessoas (DI FELICE, 2008, p. 44).

Essa mudança ofereceu um novo modo interativo de comunicação, para muito além das tecnologias analógicas, que apresentavam limitações de interação para o receptor. A comunicação digital possibilita a criação de um ambiente onde o usuário/receptor participa, intervém, articula, toma decisões; produzindo através do hipertexto narrativas; dando significado as mesmas através de suas experiências online.

\section{As Tecnologias da Informação e Comunicação e a Educação a Distância}

As Tecnologias da Informação e Comunicação ou, mais comumente, conhecidas pela expressão TICs já são bastante conhecidas nos meios da educação em geral e, em especial, na educação virtual. São apontadas como facilitadoras da aprendizagem, motivadoras dos jovens e multiplicadoras de acesso ao ensino. Cada vez mais políticas públicas, nos mais diversos níveis, têm envolvido essas tecnologias e não só na educação, extrapolam por todas as áreas especialmente referentes a iniciativas como inclusão digital, governo eletrônico, infraestrutura urbana, controle do território, segurança pública, negócios, prestação de serviços eletrônicos, entre outras. Porém, são dissimétricas as velocidades de desenvolvimento das tecnologias e das suas estratégias de implementação por parte dos gestores públicos e privados, devido a grande dificuldade encontrada, em primeiro lugar, de compreensão dos possíveis impactos na escola e nos seus agentes das mudanças culturais alavancadas pelas TICs e, em segundo lugar, mensurar corretamente o desenvolvimento tecnológico dos alunos, mas também ao ambiente escolar cada vez mais multicultural, heterogêneo, caótico, desequilibrado e dinâmico.

Desta forma, tanto do ponto de vista da reflexão teórica como da aplicação prática, uma difusão massiva das TICs - especialmente com a sua aceleração com os avanços das tecnologias móveis e wireless - necessita-se cada vez mais esforços multidisciplinares, pois não estamos falando de pressupostos banais, uma vez que as próprias noções de tempo e espaço estão sendo relativizadas com essas novas tecnologias. Daí os comportamentos de todos os agentes envolvidos que vão do fascínio acrítico à total rejeição improdutiva.

Outrossim, as TICs estão no bojo das ferramentas preconizadas por grande parte dos organismos internacionais como facilitadoras do processo ensino-aprendizagem. Por exemplo, a UNESCO tem acordos de cooperação com o governo brasileiro para a "promoção de ações de disseminação de TICs nas escolas com o objetivo de melhorar a qualidade do processo ensino-aprendizagem, entendendo que o letramento digital é uma decorrência natural da utilização frequente dessas tecnologias" (UNESCO, 2009). O próprio Ministério da Educação brasileiro tem a meta 
ousada de universalizar os laboratórios de informática em todas as escolas públicas, incluindo as rurais. É um esforço de diversos organismos para fazer convergir as diferentes mídias, TV, internet, rádio, impressos na tentativa de criar o máximo de interatividade dos conteúdos escolares utilizados no ensino presencial e à distância.

No entanto, a utilização das TICs enfrenta uma série de desafios, a UNESCO aponta três de primeira ordem, são eles: a) entender "as TICs como apenas uma parte de um contínuo desenvolvimento de tecnologias, a começar pelo giz e os livros, todos podendo apoiar e enriquecer a aprendizagem; b) ter a compreensão de que "as TICs, como qualquer ferramenta, devem ser usadas e adaptadas para servir a fins educacionais"; e, c) saber enfrentar as "várias questões éticas e legais, como as vinculadas à propriedade do conhecimento, ao crescente tratamento da educação como uma mercadoria, à globalização da educação face à diversidade cultural, interferem no amplo uso das TICs na educação" (UNESCO, 2009).

Se por um lado, as TICs são diversas e necessitam de investimento na sua adequada apreensão enquanto instrumento de ensinoaprendizagem, por outro lado, o ensino à distância, também apresenta diferentes usos de tecnologias e meios de comunicação no processo de ensinar e aprender. A começar pelo rompimento da estrutura clássica da presença frente a frente de professores e alunos, na modalidade EAD eles se encontram distanciados no espaço e no tempo. O que faz com seja necessário o pleno domínio dos instrumentos de comunicação - entre eles as TICs -, desde os ambientes on line, videoconferências, correios, telefone, materiais impressos, entre outros.

Para o funcionamento eficiente de um sistema EAD, é necessário que o processo de comunicação aconteça, ou seja, que os sujeitos participem, compartilhem e interajam entre si, o que os caracteriza como sujeitos "interagentes" (PRIMO, 2003). Conforme a tese clássica de Paulo Freire, que afirma que "a educação é comunicação, é diálogo, na medida em que não é transformação do saber, mas um encontro de sujeitos interlocutores que buscam a significação dos significados", e desta forma, não existe conhecimento sem a relação dialógica (FREIRE, 1980, p. 71). Na mesma linha, Ilana Polistchuk e Aluizio Ramos Trinta afirmam que o alicerce da comunicação é a troca de mensagens, só ela é significativa, produz sentidos, realiza a interação cotidiana e a linguística, assim como diz respeito às relações de sentido e significado (POLISTCHUK e TRINTA, 2003). Da mesma forma que a própria circulação de saber e as transmissões de informações geram um processo de comunicação, ou seja, deve ser considerada na complexidade dos processos comunicativos e não como mero mecanismo de transmissão (GUTIERREZ e PIETRO, 1994).

Assim sendo, só é possível a construção de diversos sentidos e significados na e sobre a prática pedagógica, se a entendermos como uma multiplicidade de sujeitos, de concepções e de linguagens envolvidas em um processo educativo. Afinal, são as características semióticas da linguagem que fazem com que os discursos produzidos se relacionem e signifiquem o mundo. Sendo a linguagem o instrumento primeiro de mediação das relações homem-mundo e ao mesmo tempo indissociável da comunicação, ela é o fundamento para a formação das consciências e de sua inteligibilidade, que se dá por meio da interação, do diálogo verbal entre os sujeitos. Através da atribuição de sentidos à linguagem que é possível que os humanos deem significado ao mundo e possam estabelecer relações entre si.

A linguagem é sistema autônomo de expressão, segundo Polistchuk e Trinta (2003, p. 50) ela opera como "um instrumento ao qual o ser humano recorre para conferir existência e imprimir objetividade as suas idéias, desejos, pensamentos e experiências". Somente de posse da linguagem como instrumento de comunicação que os sujeitos podem exercer a sua interlocução, poderão se informar cientificamente, produzir suas pesquisas, desenvolver seus temas acadêmicos, e, sobretudo, relacionar-se com o outro (GUTIERREZ e PIETRO, 1994).

Assim que, na grande maioria das ocasiões, o grau de sucesso e/ou fracasso de um evento de educação à distância está fortemente ligado às formas como ocorreu a comunicação entre os participantes do processo de ensino-aprendizagem. Daí a necessidade de entendermos que as TICs podem ser ferramentas importantes para o sucesso do EAD, desde que não sejam banalizadas como meros instrumentos de pacotes tecnológicos descartáveis.

\section{Os TIPOS DE LEITORES DO MUNDO CIBERNÉTICO E A EFICÁCIA DA COMUNICAÇÃO}

Se a revolução digital produziu uma mudança radical nos comportamentos sociais e nas formas de se pensar nesta virada de século, o que podemos dizer das nossas maneiras de compreender a leitura e de, literalmente, ler no ciberespaço. Afinal como já descreveu Roger Chartier em seus respeitados estudos 
sobre a leitura, ele tem buscado a reconstrução tanto "das redes de práticas e as regras de leituras próprias às diversas comunidades de leitores (espirituais, intelectuais, profissionais etc.)", como as relações dos estudos de história da leitura com três conjuntos de mudanças: as tecnológicas, as formais e as culturais (CHARTIER, 1998, p. 24).

Inspirada em algumas das descobertas de Roger Chartier, Lúcia Santaella orienta sua pesquisa para investigar "as novas formas de percepção e cognição que os atuais suportes e estruturas híbridas e alineares do texto escrito estão fazendo emergir. Que novas disposições, habilidades e competências de leitura estão aparecendo? Enfim, que novo tipo de leitor está surgindo no seio das configurações hipermidiáticas das redes e conexões eletrônicas?" (SANTAELLA, 2009, p. 16).

As mudanças tecnológicas proporcionaram uma diversificação de direções, novos braços, para a interação entre homens e máquinas, repercutindo na amplificação, profusão, disseminação e absorção da informação. No contexto das proposições de tipos de leitores e das habilidades e competências necessárias para o entendimento das configurações hipermidiáticas da atualidade, Santaella nos proporciona um olhar sobre os tipos de leitores através dos tempos, "do leitor do livro para o leitor da imagem e desta para o leitor das formas híbridas de signos e processos de linguagem, incluindo nessas formas até mesmo o leitor da cidade e o espectador de cinema, TV e vídeo" (SANTAELLA, 2009, p. 16).

É a pesquisa de Santaella que seguiremos para melhor compreendermos as fases do leitor até chegar ao momento do texto híbrido da cibernética. Segundo ela, o primeiro que surge

é o leitor contemplativo, meditativo da idade pré-industrial, o leitor da era do livro impresso e da imagem expositiva, fixa. Esse tipo de leitor nasce no Renascimento e perdura hegemonicamente até meados do século XIX. O segundo é o leitor do mundo em movimento, dinâmico, mundo híbrido, de misturas sígnicas, um leitor que é filho da Revolução Industrial e do aparecimento dos grandes centros urbanos: o homem na multidão. Esse leitor, que nasce com a explosão do jornal e com o universo reprodutivo da fotografia e do cinema, atravessa não só a era industrial, mas mantém suas características básicas quando se dá o advento da revolução eletrônica, era do apogeu da televisão. O terceiro tipo de leitor é aquele que começa a emergir nos novos espaços incorpóreos da virtualidade. (SANTAELLA, 2004, p.16)

É necessário observar que um leitor não é de nenhuma forma excludente ao outro. Muito pelo contrário,

não parece haver nada mais cumulativo do que as conquistas da cultura humana. O que existe, assim, é uma convivência e reciprocidade entre os três tipos de leitores, embora cada tipo continue, de fato, sendo irredutível ao outro, exigindo, aliás, habilidades perceptivas, sensóriomotoras e cognitivas distintas. (SANTAELLA, 2009, p. 19-20)

\section{LEITOR CONTEMPLATIVO}

O leitor contemplativo, meditativo da era pré-industrial, refere-se a uma leitura individual, solitária, em silêncio profundo. No século XII, com o surgimento das universidades, no seio da formação de uma classe burguesa, as mudanças sociais, intelectuais se intensificam, a necessidade de formar uma classe mais erudita, a sociedade que surgia pressupunha leitores e escritores nas suas mais diversas funções sociais. No século XV, os livros já eram feitos de uma película de natureza vegetal, o papel, podendo ser reproduzidos com maior rapidez. Historicamente, podemos situar o final da gestação deste leitor no Renascimento e, predominante, até metade do século XIX. Sem a premência do tempo, este é um leitor que pode comtemplar e as novas formas do objeto livro possibilitam que o tenha em suas mãos. Uma comunicação direta entre o leitor e o livro é o que se caracteriza desse período, o leitor criava o seu ritual de leitura e meditação, o fato de poder folhear as páginas, permitia idas e vindas, insinuando ressignificações da obra literária, sendo assim que, "a leitura silenciosa criou a possibilidade de ler textos mais complexos" (CHARTIER, 1997, p. 24). Os sentidos deste leitor dificilmente seriam colocados em teste pela quebra de suas noções de tempo e espaço, que respeitavam a linearidade e o processo de organização das informações, que seguem ordenadamente em parágrafos, páginas, volumes e coleções.

\section{LEITOR MOVENTE}

São as mudanças da modernidade que produzem o leitor movente, será um dos grandes artífices das grandes transformações a partir da metade do século XIX. É ele o homem que assistiu a inauguração da era da reprodutibilidade técnica $\mathrm{da}$ indústria com a possibilidade de transformar quase todos os objetos em produtos do sistema capitalista, ele sucumbe ao fascínio das aparências de democracia do acesso ao consumo, ao conforto e à cultura. Parecia que finalmente o mundo rural 
da pobreza e da miséria seria suplantado pela pujança e abundância das metrópoles que surgiam.

As grandes cidades inauguravam uma nova percepção do mundo, a noite era dominada pela eletricidade, a multidão colocava os homens lado a lado nas ruas e avenidas, no entanto, paradoxalmente, descobria-se que o a solidão era cada vez mais uma característica da modernidade. A velocidade alucinante de carros, bondes, trens passava a ditar uma perspectiva do tempo. As imagens antes estáticas agora ganhavam movimento com o cinema, logo depois o som, e mais recentemente a televisão uniu definitivamente som, imagem e individualidade. O mundo dos negócios ampliou-se exigiu mais das comunicações e dos transportes, telefone, rádio, trens, navios mercantes singravam mares e terras e o mundo foi dominado. A publicidade atinge um lugar especial nesse novo mundo, domina a cena das cidades e está presente em quase todos os escritos impressos, no cinema, no rádio, na televisão. Para Santaella, um dos principais suportes da publicidade é a fotografia "que dilata a visão humana, devolvendo ao mundo cenas, paisagens, lugares, pessoas que são duplos dele mesmo" (2009, p. 27).

É a fase da multiplicação dos meios de comunicação assumem um poder simbólico hipnótico, sedutor. Num mundo fascinado pela incessante descoberta de novos produtos e do seu recente poder de consumir, a publicidade e as novas mídias acreditam que bastaria mostrar, exibir os novos produtos que eles se transformariam imediatamente em objetos de desejo.

Este é o contexto histórico de nascimento do leitor movente, uma cidade que produz e reproduz signos imagéticos, é por ela que ele anda a tropeçar nas informações. Rapidamente, impõe-se a ele uma necessidade de se adaptar um ritmo de atenção alucinante, com objetos e imagens que vão da imobilidade às altas velocidades em instantes. É o leitor treinado nas distrações fugazes e sensações evanescentes cuja percepção se tornou uma atividade instável, de intensidades desiguais. É, enfim, o leitor apressado das linguagens efêmeras, híbridas, misturadas (...) leitor fugaz, novidadeiro, de memória curta, mas ágil (...) Um leitor de fragmentos, leitor de tiras de jornal e fatias de realidade (SANTAELLA, 2009, p. 29).

Após a sua formação no palco das grandes cidades da modernidade, o leitor movente tinha as habilidades para decifrar uma grande quantidade de signos e para transitar sem dificuldades por diferentes linguagens. Para Santaella, foi a flexibilidade desse leitor movente que abriu caminho ao tipo de leitor mais recente "o imersivo", ou seja, ele esteve preparando o despertar de uma nova sensibilidade perceptiva humana para o surgimento do leitor imersivo, que navega "entre nós e conexões alineares pelas arquiteturas líquidas dos espaços virtuais" (2009, p. 11).

\section{LEITOR IMERSIVO}

Nascido da multiplicidade de imagens sígnicas e dos ambientes virtuais de comunicação imediata, o leitor imersivo ou virtual é um novo tipo de leitor que está inserido dentro das grandes metrópoles, à vontade com a linguagem efêmera e dotado de uma sensibilidade perceptivo-cognitiva beirando o instantâneo.

Como o leitor da era digital, ele pode receber, armazenar, tratar, difundir e acessar qualquer signo - sonoro, icônico ou textual - através de um aparato tecnológico único, o computador. Sem precisar andar aos tropeços na cidade moderna, ele é o sujeito que lê os hipertextos no ciberespaço, um navegante do mundo virtual. Passo a passo, e com destreza e velocidade, ele forma os hipertextos através de uma rede de nós e nexos que os navegantes constroem ativamente a informação ou, também, pode passear livremente seguindo sua intuição.

Segundo Lúcia Santaella, o leitor imersivo, um receptor de hipermídia ou seu receptor, deflagram mecanismos, habilidades muito diferentes daquelas utilizadas pelo leitor de um texto impresso, tal como um livro. Como, também, são distintas das habilidades utilizadas pelo receptor de imagens ou espectador de cinema ou televisão. As habilidades de leitura multimídia cada vez mais se acentuam com as novas tecnologias, "nas potencialmente infinitas infovias do ciberespaço" (2009, p. 11). Este novo leitor é portador de novas formas de percepção e cognição que o habilitam a ler e escrever nos atuais suportes eletrônicos e estruturas híbridas e alineares do texto escrito, a internet e sua rede mundial é o seu palco de atuação e o mundo lhe pertence - ainda que virtualmente.

Sua leitura é livre, ou com maior liberdade, pois pode circular por rotas e direções de sentidos sem peias. É a aparente liberdade contemporânea na qual também convive o leitor imersivo, também nominada de tempos líquidos, pós-modernos, hipermodernos etc. A pulverização das verdades e falta ou não necessidade de uma única verdade, tem levado a subjetividades individualizadas com foros de única realidade correta. Apesar de não possuir as sequências formais dos livros impressos ou a lógica enfatizada dos meios de comunicação 
de massa tradicionais, nem por isso falta coerência ao mundo virtual. São lógicas particulares, traçadas ao navegar e escolher percursos, que são formadas pelo leitor imersivo. Num permanente estado de prontidão e imersão, cabe ao leitor imersivo definir em seu roteiro multissequencial o momento que sua informação está concluída. O parágrafo que antes orientava o design gráfico do livro e da leitura, agora está sendo desconstruído pelo/ para o leitor imersivo, que ao que parece não segue uma linearidade rígida, mas sim a multilinearidade. A interação com sons, imagens, documentos ou vídeos parece não ter muita diferença para o leitor imersivo.

O leitor imersivo apresenta uma grande intimidade com a leitura de diferentes signos. Essa intimidade é de tal ordem que ele manipula e cria os seus próprios conteúdos, que muito além de simples expressão pessoal criam novos nexos na rede que acabam por ter a mesma importância daqueles pelos quais ele navega. O poder simbólico que antes pertencia aos meios tradicionais de comunicação de massa, com essa produção sem respeito às hierarquias acaba por se horizontalizar. $\mathrm{Na}$ explicação de Santaella, a hipertextualidade construiu uma nova maneira de que é, de fato, uma escritura pois o nexos vão sendo associados pelo leitor-produtor. "A leitura orientada hipermidiaticamente é uma atividade nômade de perambulação de um lado para o outro, juntando fragmentos que vão se unindo mediante uma lógica associativa e de mapas cognitivos personalizados e intransferíveis" (SANTAELLA, 2009, p. 175).

Diferentemente dos leitores que o antecederam, o leitor imersivo parece não ter tempo algum para a contemplação, ele navega, perscruta, entende, busca e atua tudo ao mesmo tempo. Numa ânsia de que sempre há muito mais a ser visto, ele navega sempre sem temor de não estar na rota correta, para ele não existe o conceito de rota semiótica certa. Seus percursos são infinitos, de maneiras infinitas, no máximo ele confia parte de suas "memórias" de navegação em repositórios eletrônicos. Uma constante e confortável busca de solução de problemas e procura de significados pautam seu comportamento assinalado por esses processos inferenciais.

No entanto, Santaella (2009) não enfatiza muito as diferenças entres os três tipos de leitores, porém há habilidades que os diferem. Sua pesquisa apontou para conhecer e delimitar esse novo leitor, como se davam suas transformações sensórias, perceptivas, cognitivas e, consequentemente, também como se processaram as transformações de sua sensibilidade. Por fim, para Santaella essa multiplicidade é resultado da soma do leitor das imagens evanescentes da computação gráfica e do leitor do texto escrito que saltou do papel para a superfície das telas eletrônicas. Esse leitor imersivo está transitando pelas infovias das redes, constituindo-se como um novo tipo de leitor que navega nas arquiteturas líquidas e alineares da hipermídia no ciberespaço.

\section{Considerações finais}

Para concluir nossa reflexão acerca das possibilidades das Tecnologias de Informação e Comunicação (TICs) no contexto da Educação à Distância (EAD), ressaltamos a necessidade de que para que tenhamos um bom entendimento do fenômeno da virtualização das relações de ensino-aprendizagem é necessário que continuemos a investigar, desde os contextos históricos que foram palco do nascimento dessa nova forma de entender o mundo contemporâneo até chegar aos processos individualizados de cognição/ leitura dos usuários do ciberespaço.

Da aldeia global de McLuhan à galáxia na internet de Castells deu-se um longo processo - apesar de muitas vezes parecer tão rápido e efêmero - de produção e reprodução tecnológica e teórica para que pudéssemos absorver o mundo da cibernética, aí inclusos os da "geração internet", sim porque o conhecimento que agora parece tão disponível e fácil é fruto de profundas investigações e gigantescos investimentos da sociedade mundial.

Por outro lado, parece que dar a devida importância para as TICs como suporte e instigadoras dos processos de ensino-aprendizagens é um ponto fulcral para o bom andamento das atividades e processos do EAD. As TICs deveriam ser incorporadas à formação pedagógica dos futuros docentes do EAD, colocando a comunicação lado a lado com as disciplinas didático-pedagógicas. Ganhariam as duas áreas do conhecimento.

Por fim, a necessidade de conhecermos as formas pelas quais os usuários do ciberespaço conduzem sua navegação (aprendizagem) pode explicar muito da incomunicabilidade que, por vezes, existe entre docentes e alunos do EAD. Além de possibilitar que desenvolvamos atividades de "letramento digital" para aqueles alunos que ainda não possuem essas habilidades. 


\section{ReferÊNCIAS}

CASTELLS, M. A sociedade em rede. $1^{\text {a }}$. ed. São Paulo: Paz e Terra, 1999.

CASTELLS, M. A galáxia da internet: reflexões sobre a internet, os negócios e a sociedade. $1^{\mathrm{a}}$. ed. Rio de Janeiro: Jorge Zahar, 2003.

CHARTIER, R. A aventura do livro: do leitor ao navegador. São Paulo: UNESP/ Imprensa Oficial do Estado, 1997.

CHARTIER, R. A ordem dos livros. Leitores, autores e bibliotecas na Europa entre os séculos XIV e XVIII. Tradução de Mary Del Priori. Brasília: EDUNB, 1998.

DI FELICE, M. Das tecnologias da democracia para as tecnologias da colaboração. In: DI FELICE, M. Do público para as redes: a comunicação digital e as novas formas de participação social. $1^{a}$. ed. São Caetano do Sul: Difusão, 2008. Cap. 1, p. 17-62.

FREIRE, P. Extensão ou comunicação. $5^{\text {a }}$. ed. Rio de Janeiro: Paz e Terra, 1980.

GUTIERREZ, F.; PIETRO, D. A Mediação Pedagógica: educação a distância alternativa. Campinas: Papirus, 1994.

KERCKHOVE, D. D. A pele da cultura: Investigando a nova realidade eletrônica. $1^{a}$. ed. São Paulo: Annablume, 2009.

LEMOS, A. Mídias locativas e territórios informacionais. In: SANTAELLA, L.; ARANTES, P. Estéticas tecnológicas: novos modos de sentir. $1^{\mathrm{a}}$. ed. São Paulo: EDUC, 2008. p. 207-230.

MANOVICH, L. The Language of New Media. $1^{\text {a }}$. ed. Cambridge: MIT Press, 2001. Disponível em: http://manovich.net/LNM/index.html.

MCLUHAN, M. The Gutemberg Galaxy: the making of typographic man. $1^{a}$. ed. Toronto: University of Toronto Press, 1962. 294 p.

POLISTCHUK, I.; TRINTA, A. R. Teorias da comunicação: o pensamento e a prática da comunicação social. Rio de Janeiro: Elsevier, 2003.

PRIMO, A. F. T. Interação mediada por computador: a comunicação e a educação a distância segundo uma perspectiva sistêmico-relacional. Porto Alegre: UFRGS (Tese de doutorado em Informática da Educação), 2003. 292 p. Disponível em http:\\ www.bibliotecadigital.ufrgs.br/da.php?nrb $=0004495$ $73 \& l o c=2005 \& 1=568 \mathrm{e} 019 \mathrm{f} 14 \mathrm{c} 343 \mathrm{fc}$.

SANTAELLA, L. Navegar no ciberespaço: o perfil cognitivo do leitor imersivo. $3^{a}$. ed. São Paulo: Paulus, 2009.

SANTAELLA, L. A ecologia pluralista da comunicação: conectividade, mobilidade, ubiquidade. São Paulo: Paulus, 2010.

TAPSCOTT, D. A hora da geração digital. $1^{\mathrm{a}}$. ed. Rio de Janeiro: Agir Negócios, 2010.

TURKLE, S. Sherry Turkle: fronteiras do real e do virtual. Entrevista a Federico Casalegno. Revista FAMECOS, Porto Alegre, 1, n. 11, dezembro 1999. 117-123.

UNESCO. Padrões de competência em TIC para professores: marco político. $1^{\mathrm{a}}$. ed. Brasília: Organização das Nações Unidas para a Educação, a Ciência e a Cultura/ UNESCO, 2009. Disponível em: http://unesdoc.unesco.org/ images/0015/001562/156210por.pdf.

WEISSBERG, J.-L. Présences à distance: Déplacement virtuel et réseaux numériques. $1^{\mathrm{a}}$. ed. Paris: L`Harmattan, 1999. 304 p. Disponível em: http://hypermedia.univ-paris8.fr/weissberg/ presence/presence.htm. 